\title{
Visibilidad en la Web de los Colegios Oficiales de Aparejadores, Arquitectos Técnicos e Ingenieros de Edificación de Andalucía
}

\author{
Emilio GómEZ CoBos \\ Universidad de Granada. Dto. Construcciones Arquitectónicas \\ emiliog@ugr.es \\ Pilar MARTÍNEZ-OSORIO IBARRA \\ Dra. Documentación; Lda. Geografía e Historia \\ piosorio3@gmail.com
}

Recibido: Agosto 2015

Aceptado: Octubre 2015

Resumen: Se diseña y testa un instrumento de medida para analizar la visibilidad en la Web de los Colegios Oficiales de Aparejadores, Arquitectos Técnicos e Ingenieros de Edificación (COAATIEs) de Andalucía que contempla mecanismos para efectuar una evaluación objetiva. Se expone el desarrollo metodológico de la elección y definición de los indicadores cualitativos utilizados a los que se les asigna un valor, dentro de un rango previamente establecido, para su posterior cuantificación. Los resultados permiten conocer la visibilidad de las sedes web de estas corporaciones. Se presenta tanto la herramienta como la metodología de uso para que este procedimiento pueda ser extrapolable a otras instituciones.

Palabras clave: Arquitectura Técnica; Aparejadores; Herramienta de medida; Ingeniería de Edificación; Instrumento de medida; Evaluación web, Indicadores, V isibilidad web.

\section{Web visibility of the Official Associations of Surveyors, Technical Architects and Building Engineers of Andalusia (Spain)}

\begin{abstract}
A measurement instrument is designed and tested to analyze the Web visibility of the Official Associations of Surveyors, Technical Architects and Building Engineers of Andalusia (Spain), which includes mechanisms to make an objective assessment. In order to that, a methodological development has been performed using qualitative parameters. These parameters are assigned a value, within a previously established range, for subsequent quantification. The results provide insights into the visibility of the web sites of these corporations. The tool as well as the methodology of usage is presented so that this procedure can be extrapolated to other institutions.
\end{abstract}

Keywords: Engineering Building; Evaluation web; Indicators; Measuring instrument; Measuring tool; Project Surveyors; Technical Architecture; Web Visibility. 


\section{INTRODUCCIÓN}

Los servicios informacionales electrónicos o telemáticos que utiliza la World Wide Web (WWW), entendiéndose los mismos como fuente primordial de comunicación, se han convertido en una herramienta decisiva para la información institucional.

La explosión de la burbuja digital ha ratificado las expectativas depositadas en las nuevas tecnologías basadas en Internet, auspiciando la sustitución del tejido económico-social actual, tal y como se conocía hasta ahora, por el digital, implicando, según califican todos los expertos, cambios revolucionarios (Pinto Molina et al., 2004: 346).

Es evidente que la sociedad se encuentra ante una nueva revolución que ha transformado la estructura socio-política, cambiando las relaciones de poder y modificando las de los ciudadanos. Además, son los propios poderes públicos los que se encuentran obligados a promover, en beneficio de los administrados, las comunicaciones electrónicas (Valle García, 2013: 29). Se trata de un gran cambio social, político y económico ya que no supone una leve variación en cada una de estas relaciones sino que implica una transformación completa y profunda. Es la denominada "Sociedad de la Información y el Conocimiento".

La WWW sigue creciendo y desarrollándose y no solo por cuestiones relacionadas con las nuevas tecnologías, sino por las ventajas que indiscutiblemente ofrece. Con respecto a dichas ventajas cabe destacar una sobre todas las demás, es la inmediatez y velocidad a la que se produce la transferencia de información desde su origen hasta su posible receptor, superando la de cualquier medio tradicional.

Hasta ahora se había producido un cambio de instrumentos o dispositivos (p.ej. el correo convencional sustituyó al fax que a su vez fue reemplazado por el correo electrónico) pero gracias a la digitalización y a las redes de comunicación se ha ocasionado una profunda metamorfosis en la forma de vivir y trabajar.

En este contexto de cambios, la capacidad de adaptación de las empresas e instituciones reviste una importancia capital en lo que a la competitividad se refiere, ya que las acciones de sensibilización de toda esta transformación son la clave para provocar la modificación y evolución de las actitudes del entramado empresarial e institucional.

Es pues imprescindible que, los dirigentes de estas entidades con puestos de responsabilidad, conozcan la importancia que está adquiriendo la información electrónica, sus ventajas y beneficios, y adopten los pasos a seguir para su implantación en sus entornos de trabajo, apostando firmemente por las Tecnologías de la Información y la Comunicación (TIC). Para ello tendrán que asentar las bases para que sus empresas e instituciones las incorporen allí donde tengan cabida, conviviendo de manera natural con los métodos tradicionales.

Aunque en algunos casos, puede existir una brecha para el desarrollo de las TIC 
dentro de este entorno empresarial e institucional debido al desconocimiento de las posibilidades que una determinada tecnología puede ofrecer o bien, como apunta Martínez Pestaña (2013: 20), a causa del "retraso en la puesta en marcha de la Agenda Digital" en España.

También existe la creencia, en algunas organizaciones, que ciertas tecnologías no son aplicables ya que quedan demasiado lejanas en su quehacer cotidiano, motivo por el cual se desaniman a emprender el camino de la adaptación tecnológica. Estas organizaciones, independientemente de su tamaño, se enfrentan a conceptos como: rentabilidad, calidad, tecnología y desarrollo sostenible, y olvidan que un sistema eficiente de gestión de la información electrónica, diseñado a medida de sus procesos productivos puede ayudarles a desafiar la llamada globalización.

Hoy por hoy, cualquier actividad empresarial, institucional o corporativa implica manejar una cantidad significativa de información. Por ello, es de máxima importancia almacenar y, sobre todo, estructurar dichos datos en un soporte informático, lo que permite, entre otros beneficios, un mejor nivel de acceso a los mismos y un incremento general de los niveles de eficacia.

La digitalización de estas entidades se está produciendo de forma gradual provocando consecuentemente el aumento de informatización de la información.

En los tiempos actuales, no cabe duda que los servicios de información telemáticos de todas estas entidades que usan la World Wide Web como conducto de comunicación son un instrumento fundamental para la información institucional (Pinto Molina et al., 2004: 346). Por todo ello es de suma importancia que dichos servicios informacionales tengan presentes los argumentos comentados anteriormente en cuanto a su proyección hacia el exterior, para lo cual es indispensable disponer de una cualidad primordial, la "visibilidad" en Internet. Éste es un objetivo primordial que deben fijarse todas aquellas entidades que hayan desarrollado un sitio web si quieren lograr aumentar su presencia en los motores de búsqueda (Montenegro, Ochoa y Mejía, 2014: 139).

Al mismo tiempo, parece lógico que se elaboren métodos eficaces para evaluar tanto los sistemas como las fuentes de información en la red, siendo el analista quien deba realizar esta labor de forma individualizada. El desarrollo de esta tarea deberá sustentarse en una metodología que emane de las propias características de la información digital, así como en los estándares que proponen parámetros e indicadores previamente establecidos, con el objeto de lograr una evaluación rigurosa e independiente (Ayuso García y Martínez Navarro, 2005: 23). En esta misma línea Merlo Vega (2003: 101) afirma que la evaluación de páginas web es igualmente necesaria por motivos cuantitativos y cualitativos.

El propósito de este trabajo es diseñar una herramienta, orientada principalmente a asociaciones profesionales, que pueda servir para medir la visibilidad web y permita aumentar la calidad en la transmisión de la información electrónica basada en plataformas con el objeto de que ésta llegue fácilmente a un 
mayor número de usuarios.

Para probar su validez se realiza un estudio de caso de los ocho Colegios Oficiales de Aparejadores, Arquitectos Técnicos e Ingenieros de Edificación (en adelante COAATIEs) de Andalucía. El propósito es, que esta herramienta de evaluación, pueda ser extrapolable a otras entidades, instituciones o colectivos de rango similar.

\section{MARCO TEÓRICO: REVISIÓN DE LA LITERATURA}

Una de las definiciones que creemos más acertadas sobre visibilidad web la aportan Drèze \& Zufryden (2004, citados en Smithson, Devece y Lapiedra, 2010: 1577) refiriéndose a ella "como el grado de facilidad con el que un usuario, a través de una referencia en línea, encuentra el sitio web de una empresa $u$ organización". Aunque debemos tener en cuenta otros términos relacionados con la visibilidad web como son la presencia, accesibilidad, usabilidad, buscabilidad, ubicuidad, findability (encontrabilidad), posicionamiento o metadatos, que están estrechamente vinculados a ella y han servido de base para confeccionar el instrumento de medición y evaluación. Vamos a delimitar cada uno de ellos.

- La presencia implica que la información que sea realmente de interés para el usuario debe estar fehacientemente disponible. En este sentido "la visibilidad de la información sobre investigación tiene como precondición que esté disponible en la World Wide Web. Si dicha información no está disponible, no puede ser consultada" (Pinto Molina et al., 2004: 351).

- La accesibilidad requiere que la información sea presentada u ofrecida de forma adecuada para que sea asequible a través de los buscadores (Lawrence y Giles, 1999: 109), siendo este sistema en cuanto a búsqueda de información el más usado por los usuarios.

- La usabilidad está relacionada con el diseño web y es un término tratado y debatido por numerosos autores (Badre, 2002; Brink, Gergle y Wood, 2002; Chandler y Hyatt, 2002; Graham, 2002; Holmes, 2002; Krug, 2001; Nielsen y Tahir, 2003; Pearrow, 2002; Spool, 1999; Wroblewski, 2002), siendo Jakob Nielsen el paradigma por excelencia de la usabilidad web. Este autor asocia este término con el grado de facilidad de uso de la interfaz ${ }^{1}$ que conlleva una cierta rapidez de movimiento entre sitios, lo cual provoca en el usuario satisfacción inmediata (Nielsen, 2000: 10). Hemos podido constatar que la usabilidad tiene una gran interrelación con la calidad global y sectorial en Internet, tema que ha sido objeto de diversos estudios y monografias (Clauson, 1999; Dustin, Rasca y McDiarmid, 2002; Jiménez Piano y Ortíz-Repiso

1 Este instrumento de comunicación máquina-usuario, debe estar respaldado de un aceptable hardware y software, que posibilite su puesta en valor. 
Jiménez, 2007) y que sigue suscitando el interés de numerosos autores (DeJuanas et al., 2012; Grávalos Macho, 2013; Lara Navarra, Francesc y Josep M., 2010; López, Palacios y Mateos, 2013; Rodríguez Martínez, Codina y Pedraza Jiménez, 2012).

- La "encontrabilidad" (Morville, 2004: párr. 10) es la propia esencia de un Sistema de Información (SI) y cobra, por razones obvias, especial importancia, desde la perspectiva de la Recuperación de la Información (RI). Si la información web no es visitada, el sistema no cumpliría con la función fundamental para la que fue creado. Si tenemos en cuenta que para encontrar la información en la web se utilizan buscadores que mediante algoritmos la recuperan, debemos ofrecerla de forma concreta y pertinente para facilitar dicha función.

- Otro elemento imprescindible para que nuestro sitio web consiga un buen nivel dentro de los buscadores es el indicador de posicionamiento. Es interesante el desglose que al respecto hace Codina (2004: 2) en base a si dicho posicionamiento se considera planificado natural, planificado fraudulento o planificado ético.

Pero no debemos confundir posicionamiento con popularidad o impacto ya que son dos conceptos distintos aunque relacionados entre sí. El primero tiene que ver con el número de enlaces que recibe un sitio web y el segundo, con el valor que adquiere su contenido, además del propio valor de dichos enlaces. En definitiva, el posicionamiento web es el resultado de la recuperación de la información en las bases de datos de los grandes motores de búsqueda de Internet.

La adaptación de la información de los sitios web para que aparezcan en las primeras posiciones de los resultados de búsqueda, es conocida como SEO (Search Engine Optimization): Optimización para Motores de Búsqueda (Boutet y Quoniam, 2012: 443-445). El sistema consiste en aplicar diversas técnicas tendentes a lograr que los buscadores de Internet sitúen una página web en las primeras posiciones de sus listas de resultados para determinados términos y ecuaciones de búsqueda. También se entiende como las técnicas de desarrollo web utilizadas para mejorar la posición de un determinado sitio web en la lista de resultados de los motores de búsqueda que en inglés se identifican como SERP's (Search Engine Result Pages) (Gonzalo Penela, 2004: párr. 2-3). La aplicación de técnicas SEO es habitual en los sitios web que ofertan productos o servicios en los que existe mucha competencia y consiste en posicionar sus páginas sobre las de sus competidores en la lista de resultados (SERP's). La tarea es compleja ya que el posicionamiento implica al código de programación, al diseño y a los contenidos.

Al hablar de estrategias SEO debemos mencionar las palabras clave (keywords). Aunque Google ya no indexa estas palabras (Google: el blog para webmasters, [en línea]), otros buscadores sí lo hacen. Además para autores 
como Gonzalo Penela (2004: párr. 21) su importancia es tal que son consideradas como el factor más importante dentro del posicionamiento en los buscadores y forman parte de lo que este mismo autor denomina on the page, es decir, que están bajo el control del webmaster. Un estudio interesante sobre la elección de palabras clave para el posicionamiento web nos lo ofrecen Marcos et al. (2006) en un artículo publicado en Hipertex.net (Anuario Académico Sobre Documentación Digital y Comunicación Interactiva) de la Universidad Pompeu Fabra.

Otro elemento que tiene relevancia a la hora de obtener un mejor posicionamiento es la optimización del título (title) ya que es lo que los buscadores muestran en las listas de resultados. Es, por tanto, un indicador primordial para aumentar la visibilidad de la sede web a través de los propios motores de búsqueda y de las agencias de evaluación (Ayuso García y Martínez Navarro, 2006: 19).

- Por último vamos a hacer referencia a las metaetiquetas (metatags) ya que ofrecen información sobre el sitio web en el que se incrustan.

El término "metadatos" no tiene una definición única. Una de las más difundidas y aceptadas lo refiere como datos sobre datos, aunque también encontramos otras como información sobre datos, datos sobre información e información sobre información. Según Fuentes Martinez (2005: 163), los metadatos hacen referencia a cualquier dato que pueda ayudar a la identificación, descripción y localización de la información electrónica en la red, abarcando los datos asociados tanto a un sistema de información como a un objeto de información, con la finalidad de descripción y administración.

Existen varios tipos de metadatos cada uno con un esquema descriptivo específico. Así tenemos metadatos referidos a los contenidos (concepto), a los aspectos formales (tipo, tamaño, fecha, lengua, etc.), a la información del copyright, a la información de la autentificación del documento o recurso o a la información sobre el contexto (calidad, condiciones o características de acceso, uso, etc.).

Podemos destacar, entre los más importantes, meta title (nombre dado a un recurso), meta description (descripción del contenido de la página), meta keywords (palabras clave que describen el contenido), la etiqueta meta language (idioma de la página) y meta robots (etiqueta que indica al buscador si se desea indexar la página y/o se desean seguir los links) (Gonzalo Penela, 2004: párr. 15).

En este sentido son numerosas las clasificaciones establecidas sobre tipos de metadatos, según se refieran a aspectos de forma, funcionalidad, nivel de estructuración de los datos, persona o entidad que los origina, etc., entre las que señalamos la de Lamarca Lapuente (2013: párr. 10) y la de las autoras Angelozzi y Martín (2011) quienes realizan un análisis y comparación de metadatos para la descripción de recursos electrónicos en línea. 
En cuanto a una normalización de los metadatos, una de las iniciativas más conocida es la que propugna la Dublin Core Metadata Inititive (DCMI) ${ }^{2}$, centrándose en los metadatos descriptivos.

En definitiva lo que se pretende con los metadatos es dotar a la web de significado. Para lograr una mejor recuperación de la información, en la mayoría de los casos, no basta sólo contar con una buena estructura de la página sino que es necesario el uso de metadatos que faciliten este proceso de forma sencilla (Senso Ruíz y Rosa Piñero, 2003: 97). La idea de mejorar la efectividad en la recuperación de datos converge con la utilización de los metadatos: información sobre el contenido y el contexto de documentos digitales (Pinto Molina, García Marco y Agustín Lacruz, 2002: 99) base de la web semántica ${ }^{3}$.

Abordando de forma más concreta la visibilidad web, objeto central de este estudio, queremos citar a Castillo Blanco, Martínez de Pablo y Server, (1999: 325), para los que la heterogénea e ingente cantidad de recursos informativos que actualmente existen, suponen un gran problema de acceso a la información relevante (fiable y útil) para los sistemas de recuperación de la misma, aspecto este a considerar a la hora de hacer visibilidad.

Pero, ¿cómo hacer visibilidad?. Baeza Yates y Rivera Loaiza (2002: párr. 15), se plantean una batería de interrogantes sobre distintas circunstancias que aportan bastante claridad al respecto, como por ejemplo: ¿encontrará el sitio un buscador?, ¿existen trabas a los buscadores para entrar en el sitio?, ¿la página principal contempla el texto correcto?, ¿se puede encontrar el sitio imaginando que palabras usarán los usuarios?, ¿queda el sitio bien ubicado en una búsqueda?, ¿es un sitio ligero?, ¿es el diseño compatible con todos los navegadores?.

Aparte de estos interrogantes podemos considerar otros parámetros básicos para alcanzar la visibilidad, a saber: los motores de búsqueda, el intercambio de enlaces, las estrategias virales, las relaciones públicas, los medios tradicionales, la publicidad a través de e-mail y la publicidad pagada. También podemos tener en cuenta el PageRank (PR) de Google, que se define como un dato numérico que hace referencia puntual a la importancia que una página tiene en la web.

Siguiendo con los indicadores de visibilidad, también debemos hacer referencia al Web Impact Factor (WIF) ${ }^{4}$. La idea del WIF está basada en el Factor de Impacto (FI) de Garfield en las publicaciones periódicas, en el que dicho factor en

\footnotetext{
${ }^{2}$ Iniciativa de metadatos de Dublin Core, http://dublincore.org/ [Consulta: 19/03/2015]

${ }^{3}$ El precursor de la idea, Berners-Lee, intentó desde el principio incluir informaciones semánticas en la creación de la WWW, pero por diferentes causas no fue posible. Introdujo la Web semántica para recuperar esta omisión.

${ }^{4}$ (FIW) Factor de Impacto Web en lengua española.
} 
su cálculo tomaba en cuenta la relación existente entre las citas que reciben los artículos de la publicación en estudio y el número de artículos publicados. Con la aparición de las nuevas tecnologías, se hizo necesaria la creación de un índice similar para la evaluación de la literatura científica ubicada en los nuevos medios, así nos encontramos inicialmente con la valoración del impacto de la información en Internet (Rodriguez i Gairín, 1997: 175) y con el Factor de Impacto Web (Ingwersen, 1998: 239), el cual se basa fundamentalmente en el análisis de enlaces, aunque la idea ya se fraguó durante los trabajos sobre "webmetría" desarrollados con anterioridad de este último autor junto a Almind (Almind e Ingwersen, 1997: 404). Más tarde Vanti, Costa y Oliveira da Siva (2013), publicaron un estudio sobre la revisión de la fórmula originaria empleada para el WIF, en el que afirmaban que aquella no correspondía con la realidad de sus estudios, concluyendo que era más acertado trabajar con una renovada versión de la fórmula del WIF: número de enlaces totales (citas recibidas) al sitio web, dividido entre el logaritmo natural (LN) del número de páginas de dicho sitio.

$$
W I F=\frac{n^{\circ} \text { de enlaces recibidos }}{L N\left(n^{\circ} \text { de páginas del sitio }\right)}
$$

Para terminar este apartado, será de gran ayuda, tener presentes las dieciséis reglas promulgadas por varios autores (Bhargava, 2006; Owyang, 2006; Olthius, 2006; Baker, 2006; Odden, 2006) ${ }^{5}$ para mejorar lo que se conoce como Social Media Optimization (SMO), Optimización Social de Medios-Internet, similar al SEO visto anteriormente, y que son:

1. Incrementar la enlazabilidad (linkability).

2. Facilitar el etiquetado (tags).

3. Premiar los enlaces que nos hagan otros.

4. Ayudar a que nuestro contenido viaje (enviar contenidos a sitios o blogs relevantes).

5. Fomentar el mashup (híbridos).

6. Ser un recurso útil para los usuarios.

7. Premiar a los usuarios útiles y valiosos.

8. Participar en la comunidad.

9. Saber cómo llegar a la audiencia.

10. Crear contenidos.

11. Ser auténticos.

12. No olvidar nuestras raíces y ser humildes.

${ }^{5}$ Las cinco primeras reglas le corresponden a Bhargava, la seis y la siete a Owyang, la ocho, nueve, diez y once a Olthius, la doce y trece a Baker, y la catorce, quince y dieciséis las agregó Odden. 
13. No temer a probar cosas novedosas.

14. Desarrollar estrategias para el SMO.

15. Escoger las tácticas sabiamente.

16. Hacer del SMO parte de nuestro proceso.

\section{MATERIAL Y MÉTODO}

La metodología que hemos utilizado en la investigación es de orientación aplicada, ya que a partir de los indicadores sobre visibilidad web, que aportan valor y métrica, obtenidos de la revisión bibliográfica de la literatura especializada, hemos testado los sitios web de los Colegios Oficiales de Aparejadores, Arquitectos Técnicos e Ingenieros de Edificación de Andalucía.

Para la elaboración de este trabajo se observaron una serie de etapas, estructuradas en el tiempo, que describimos a continuación:

1. Revisión bibliográfica. En esta fase se analizó la literatura especializada para obtener una serie de indicadores y parámetros utilizados posteriormente para la evaluación de los sitios web. Se procedió a revisar la bibliografía sobre las materias objeto de este estudio en las bases de datos ISI, LISA, CSIC (ISOC e ICYT), WOS, en los repositorios e-LIS, DOIS y DIALNET, así como en Google Académico. Para el mantenimiento, organización y maquetación de las fuentes consultadas, se utilizó el gestor de referencias bibliográficas Mendeley. 2. Tras la revisión de la bibliografía manejada, se compuso el marco teórico de esta investigación anteriormente explicitado. Una vez realizada esta labor, y teniendo en cuenta la variable principal que compone este estudio: la visibilidad, sin olvidar otras relacionadas con esta, como la accesibilidad y la usabilidad, se generaron unos indicadores o parámetros deducidos de la conceptualización de dicho marco teórico, componiendo así la lista de criterios para la evaluación. A su vez, algunos de estos indicadores se agruparon en subcategorías atendiendo a su afinidad en cuanto a su función tecnológica o formal.

3. El siguiente paso fue determinar la muestra de estudio. El universo de la investigación está constituido por las plataformas web de los ocho Colegios Oficiales de Aparejadores, Arquitectos Técnicos e Ingenieros de Edificación de Andalucía que conforman el Consejo Andaluz.

4. Para establecer la taxonomía de los elementos de análisis, utilizamos la misma terminología nominal que usan Rodríguez-Martínez, Codina y PedrazaJiménez (2012: 64) en cuanto a la jerarquía que ocupan los mismos, es decir, consideramos como dimensión principal la propia visibilidad, como parámetros secundarios los cuatro grupos en los que la subdividimos: posicionamiento web, metadatos, buscador y metaetiqueta robots y como indicadores los ítems evaluables agrupados según los parámetros establecidos. 
Aunque hay que tener muy presente el sujeto final para el que se elabora la hoja de evaluación, y en base al tipo de información o servicio que se va a evaluar, diseñar la herramienta, tal y como sugiere Cooke (2001, citada en Merlo, 2003: 103) en su guía sobre estrategias para evaluar la información accesible en Internet. En este punto es donde se ha recurrido a nuestra experiencia profesional en cuanto al conocimiento del sistema estructural de las corporaciones objeto de estudio.

5. Posteriormente utilizamos la aplicación informática Microsoft Excel, para diseñar la plantilla u hoja de evaluación, componiendo una hoja de cálculo que contemplara jerárquicamente los cuatro grupos de parámetros principales junto con los subgrupos e indicadores, elegidos en función de la principal variable dimensional objeto de esta investigación: la visibilidad.

Queremos indicar que la comprobación de la actualización de los contenidos de los sitios web se realizó periódicamente mientras duró la investigación.

- Posicionamiento web. Este grupo se subdividió en cuatro apartados.

a) Generales: indicadores 1.01 al 1.10 (Ayuso García y Martínez Navarro, 2006; Calderón Rehecho, 2005; Codina, 2004; Codina y Marcos, 2005; DeJuanas et al., 2012; Gonzalo Penela, 2004; Sanz Caballero y Faba Pérez, 2012). Valoramos la sencillez y claridad de las URL de las páginas, preferentemente si utilizaban no más de dos palabras, siendo una de ellas el nombre propio del Colegio y la otra una característica que le identificara, por ejemplo, la provincia. En el uso de palabras clave (keywords), se comprobó si existían o no, y en caso afirmativo que su densidad no sobrepasara el $10 \%$ del total de palabras de la página, ya que algunos buscadores pueden considerarlo spam. En concreto, y en base a la propuesta de los autores antes mencionados, valoramos con 1 punto entre $2-7 \%$, con 0,66 puntos entre $7,1-8,5 \%$, con 0,33 puntos los resultados comprendidos entre $1-2 \%$ y $8,6-10 \%$, y 0 puntos a partir del $10 \%$. Así mismo se dio valor a las cadenas de palabras clave ya que las búsquedas son así más refinadas, siendo más útil optimizar para cadenas de 2 , 3 y hasta 4 palabras clave, como si se tratase de una sola, que optimizar para una sola palabra aislada. También es importante la transparencia, es decir, que por lo menos el $50 \%$ del contenido de la página tenga relación con la temática principal de la misma y que contenga la imagen de la institución (logo y nombre completo) para poder identificarla correctamente. La existencia de enlaces a otras páginas relacionadas con nuestra web nos ayudará a determinar el tema y, en este sentido, se penalizaran los links a páginas que puedan ser sancionadas por los buscadores.

La popularidad, o sea, la cantidad de enlaces hacia nuestra página (backlink) es fundamental para ganar visibilidad, siendo estos enlaces muy valorados, ya que tienen una gran relevancia a la hora de las búsquedas relacionadas. Para 
monitorizar los backlink hemos utilizado la herramienta Open Site Explorer de $\mathrm{MOZ}^{6}$. También se ha tenido en cuenta si el buscador redirecciona correctamente a la web institucional cuando en la barra de direcciones se omite "www" y viceversa, pues de lo contrario puede dar problemas de contenido duplicado.

b) Estructura y navegación: indicadores 1.11 al 1.13 (Ayuso García y Martínez Navarro, 2006; De-Juanas et al., 2012; Smith, 1997). Consideramos básica la ubicación del contenido en la interfaz ya que la estructuración en niveles jerárquicos facilita la navegación entre las distintas zonas o páginas. Valoramos la existencia de un mapa web que ayude a localizar la información. También es recomendable que existan enlaces de texto ya que de esta forma el buscador puede llegar a todos los apartados de la web. Se interpretó de forma positiva la aparición en la página de alguno de los iconos de la normativa WCGA 2.0 - WAI (Web Accesibility Initiative) del Consorcio de la World Wide Web (W3C), ya que indican su cumplimiento.

c) Elementos multimedia: indicador 1.14 (Ayuso García y Martínez Navarro, 2006). Las fotos o imágenes de las páginas testadas, deben de ofrecer un texto alternativo al situar el ratón sobre ellas, pues para los buscadores tiene relevancia, y ayuda a mejorar el posicionamiento web.

d) Difusión: indicadores 1.15 al 1.21 (Ingwersen, 1998; Rodriguez i Gairín, 1997; Sanz Caballero y Faba Pérez, 2010; Cordón García et al., 2012). En este apartado se contemplaron tanto el PageRank de Google como el Factor de Impacto Web (FIW). Éste último se obtuvo dividiendo el número de enlaces externos que recibe una sede o dominio entre el logaritmo natural (LN) del número de páginas de dicha sede o dominio (Vanti, Costa y Oliveira da Siva, 2013), indicando una proporción 1:1 entre visibilidad y tamaño. Así mismo se consideró apropiado establecer un indicador de estimación del tráfico, es decir, el análisis de las visitas a las páginas. Para su evaluación recurrimos al Ranking Global Alexa que ofrece una lista mundial de posición. Se estimó también si el sitio estaba en el directorio DMOZ ya que tanto Google como otros buscadores lo tienen en cuenta.

Otro aspecto importante si pretendemos tener visibilidad en el exterior, es la presencia en las redes sociales más usuales (Facebook, Twitter, LinkedIn, Youtube, etc.), por lo que valoramos si la institución auditada estaba presente en alguna de ellas. También comprobamos si en el código fuente de la página se utilizaban metadatos sociales (p.ej. eg:Title o twitter:Title, etc.) ya que favorecen que nuestros contenidos sean más y mejor compartidos en las redes sociales. Para finalizar este apartado, se añadió un indicador bastante

${ }^{6}$ Open Site Explorer es una herramienta creada por SEOMoz que permite realizar un estudio de los enlaces entrantes o backlinks de otros sitios hacia nuestra web. https://moz.com/ 
relevante actualmente como es la optimización del sitio web para su uso en dispositivos móviles (smartphones, tablets, etc.), como por ejemplo si se usa CSS para móviles, etiqueta META VIEWPORT, uso de Flash, redireccionado para móviles, o uso de Responsing Web Design ${ }^{7}$.

- Metadatos: indicadores 1.22 al 1.28 (ISO 15836:2009; ANSI/NISO Z39.85-2012, DCMI-The Dublin Core Metadata Initiative; Lamarca Lapuente, [en línea]; Martínez Usero, 2006). A la hora de la elección de los indicadores que componen este parámetro y dentro de la gran variedad existente de metadatos, se tuvo muy en cuenta la aplicación final a la que va dirigida la evaluación de visibilidad web que se realiza. De los 15 elementos básicos recogidos en Dublin Core Metadata Element Set (DCMI), consideramos seis metadatos de forma individual, por ser estos los más adecuados para medir la visibilidad. El resto de elementos se recogieron en un solo indicador. Este grupo quedó dividido en cuatro apartados: Contenido, Propiedad intelectual, Instanciación y otros Metadatos.

- Buscador: indicadores 1.29 al 1.33. Los buscadores son uno de los recursos más rentables para hacer visible nuestro sitio en Internet, por lo que es importante aparecer en los primeros puestos de las listas indexadas que proporcionan cuando se demanda información, siendo primordial estar en la primera página de relevancias. Los motores de búsqueda elegidos fueron Google, Bing y Yahoo, comprobando si les era fácil encontrar los sitios web requeridos y que posición ocupaban dentro del listado de relevancias, usando los términos, tanto en su conjunto como por separado, contenido en el nombre de las instituciones a localizar. En cuanto a la forma que tienen estos buscadores de encontrar los sitios web, nos referiremos al proceso de "crawling" por el cual los "bots"8 indexan una página consiguiendo mayor visibilidad. Para tener buenos resultados en este proceso es importante no poner trabas, como por ejemplo la navegación flash, los frames o la utilización de JavaScript. Por otro lado, consideramos que un buen uso del código estándar XHTML así como el empleo de estilos CSS, beneficia a las lecturas de los motores de búsqueda, por lo que pasamos los test específicos on line del consorcio W3C a los sitios web de los Colegios.

- Metaetiqueta "Robots": indicador 1.34. Esta etiqueta se encarga de indicar a los motores de búsqueda (crawler) ${ }^{9}$ qué tipo de permiso tienen para indexar la información que contiene una página web, por lo que su utilización es

\footnotetext{
7 Responsive Web Design (RWD), Diseño Web Adaptable: filosofía de diseño y desarrollo cuyo objetivo es la adaptación de la apariencia de las páginas web a los dispositivos móviles.

${ }^{8}$ Bots: Diminutivo de Robots.

${ }^{9}$ Robot que indexará varias páginas de una web, siguiendo los enlaces que en ésta aparezcan.
} 
fundamental para obtener visibilidad. Aquí se establecieron cuatro indicadores con calificaciones correlativas $(\mathrm{A}=0 ; \mathrm{B}=0,33 ; \mathrm{C}=0,66$ y $\mathrm{D}=1)$. Véanse en el modelo de evaluación (tabla 2).

6. Una vez estructurada la plantilla de trabajo, se procedió a conformar su contenido plasmando en ella los enunciados de los distintos indicadores que componen el modelo de evaluación. Posteriormente se comenzó con el proceso de recogida de datos de los sitios web de las instituciones a evaluar, dando forma al estudio de caso. El proceso de verificación y valoración de los indicadores se contabilizó en unas casillas ex profeso a modo de formulario con marcas.

En cuanto al sistema de medida llevado a efecto, después de revisar los métodos utilizados por otros investigadores, decidimos optar por un sistema mixto de evaluación, utilizando variables cualitativas con tratamiento cuantitativo de los datos. A saber, para los indicadores que conformaban variables dicotómicas (NO/SÍ; FALSO/VERDADERO; etc.), les otorgamos 0 ó 1 puntos, y para los indicadores que admitieran variables policotómicas, la calificación se dividió en cuatro tramos con puntuaciones respectivas de: 0 ; 0,$33 ; 0,66$ y 1 punto (de peor a mejor).

Por último, en el modelo de evaluación se incluyeron unas celdas en donde se fue anotando la puntuación individual de cada indicador, así como los subtotales resultantes para cada parámetro, y el total global, pudiendo alcanzar un máximo de 34 puntos.

La recogida de datos se concentró en los meses de febrero a mayo de 2015, y su análisis y tratamiento durante mayo-julio de 2015, con el fin de garantizar la actualidad de la evaluación.

\section{RESULTADOS}

En realidad se han obtenido dos tipos de resultados, por un lado la propia herramienta de evaluación, que se transcribe mediante representación tabulada y que exponemos en la tabla 1 de este documento y por otro lado, los resultados obtenidos con la aplicación de esta herramienta a los sitios web de los COAATIEs de Andalucía. La Hoja de Evaluación (Tabla 1) contempla un total de 34 indicadores agrupados en 4 parámetros diferentes que componen la variable dimensional principal: la visibilidad, quedando desglosada de la siguiente manera:

- Posicionamiento web (16 indicadores)

- $\quad$ Generales (9 indicadores)

- $\quad$ Estructura y navegación (3 indicadores)

- $\quad$ Elementos multimedia (1 indicador)

- Difusión (3 indicadores) 
- Metadatos (DCMI) (15 indicadores)

- $\quad$ Contenido (7 indicadores)

- $\quad$ Propiedad intelectual (4 indicadores)

- Instanciación (4 indicadores)

- Buscador (5 indicadores)

- Metaetiqueta "Robots" (1 indicador)

Se diseñó una plantilla tabulada en ocho columnas y varias filas. En la primera fila se escribió el nombre del Colegio y la URL de su sitio web. La siguiente se usó como cabecera para colocar los titulares de las columnas propuestas, así tenemos la columna REGLAS donde aparecen aquellas reglas, normas, pautas, etc. que se aplican al indicador en cuestión. A continuación figura CÓD., es decir, un código numeral ordinal que se vincula unívocamente a un indicador concreto. En la columna que sigue, se dispone la VISIBILIDAD que es la variable dimensional principal. En ella aparecen los textos resumidos de los indicadores que se han elegido. En las siguientes cuatro columnas se implementaron las casillas de verificación, donde se marcarán las respuestas o datos emanados de los indicadores correspondientes. Por último, se agrega una columna que recoja los dígitos que representan la puntuación obtenida, subtotalizando parciales según apartados. Para finalizar en la casilla inferior derecha aparece la calificación total que obtendrá el sitio web evaluado.

Tabla 1. Hoja de Evaluación. Indicadores

Métrica de evaluación, según los siguientes valores:
$\mathbf{A}=0 \quad$ (Deficiente / No aceptable / NO cumple / NO existe / Falso)
$\mathbf{B}=0,33$ (Regular / Aceptable con mejoras)
C $=0,66$ (Bien / Bueno / Bastante aceptable)
$\mathbf{D}=1 \quad$ (Muy bien / Muy bueno / Excelente / SÍ cumple / SÍ existe /
Verdadero)

Las casillas se señalarán con una $(\mathrm{X})(\otimes)$ dependiendo de la calificación otorgada. Solo se puede rellenar una sola casilla. Las casillas $\mathrm{B}$ y $\mathrm{C}$ pueden no existir, si la respuesta del indicador es del tipo NO cumple / NO existe / Falso o SÍ cumple / SÍ existe / Verdadero.

\begin{tabular}{|c|c|c|c|c|c|c|c|}
\hline \multicolumn{3}{|c|}{ COAATIE: } & \multicolumn{5}{|c|}{ URL: } \\
\hline REGLAS & CÓD & VISIBILIDAD & A & B & C & D & Pto \\
\hline \multicolumn{8}{|c|}{ Posicionamiento web } \\
\hline \multicolumn{8}{|c|}{ Generales } \\
\hline--- & 1.01 & $\begin{array}{l}\text { La URL es corta, clara y fácil de } \\
\text { recordar. }\end{array}$ & $\square$ & $\square$ & $\square$ & $\square$ & \\
\hline
\end{tabular}




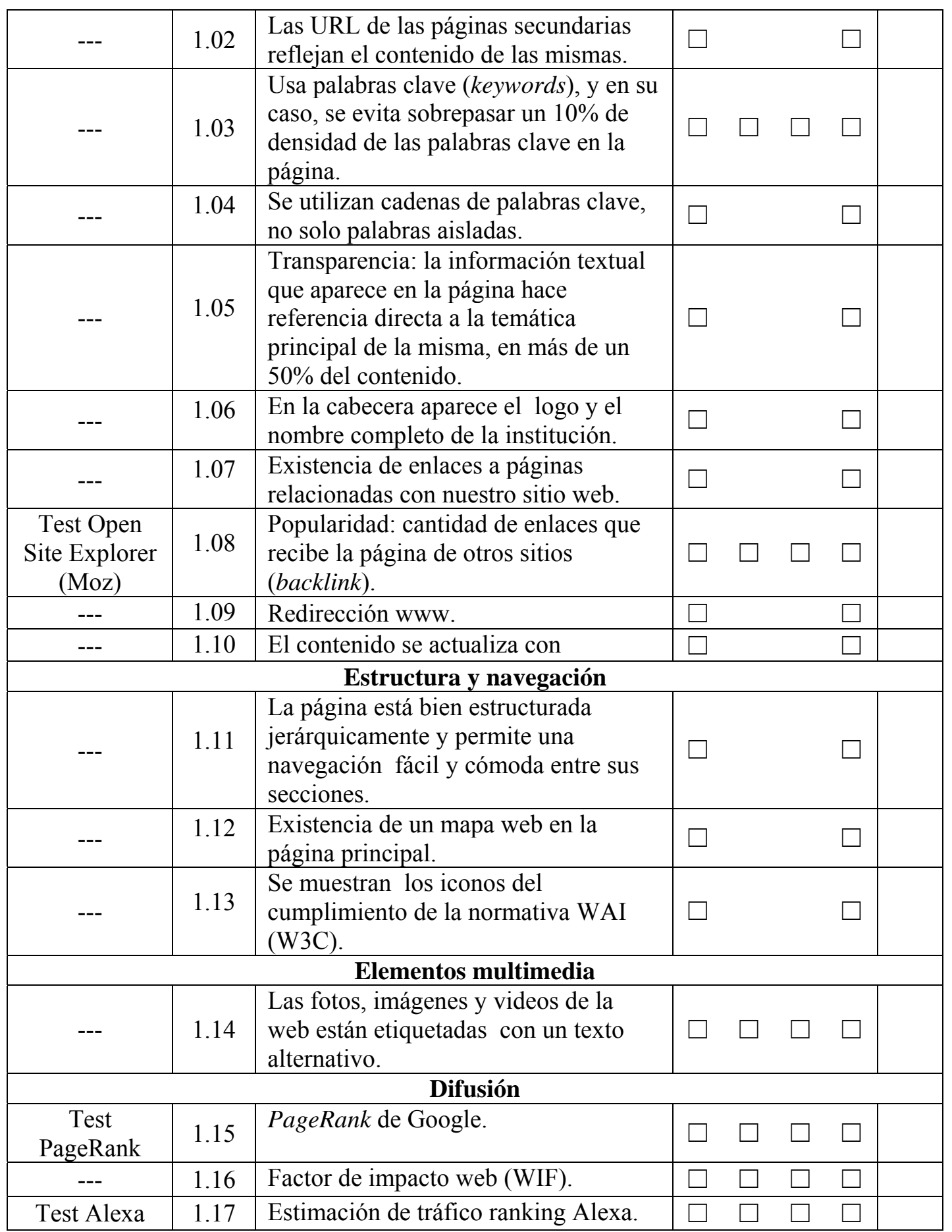




\begin{tabular}{|c|c|c|c|c|}
\hline--- & 1.18 & $\begin{array}{l}\text { El sitio web está dado de alta en el } \\
\text { directorio DMOZ. }\end{array}$ & $\square$ & $\square$ \\
\hline--- & 1.19 & $\begin{array}{l}\text { La página tiene vínculos de acceso a } \\
\text { las redes sociales de la institución. } \\
\text { (Facebook, Twitter, LinkedIn, ...) }\end{array}$ & $\square \square \square$ & $\square$ \\
\hline--- & 1.20 & $\begin{array}{l}\text { Existen metadatos sociales para } \\
\text { Facebook, Twitter, ... }\end{array}$ & $\square$ & $\square$ \\
\hline--- & 1.21 & $\begin{array}{l}\text { Optimización del sitio web para su uso } \\
\text { en dispositivos móviles. }\end{array}$ & $\square \quad \square \quad \square$ & $\square$ \\
\hline \multicolumn{5}{|c|}{ Subtotal puntuación Posicionamiento web: } \\
\hline \multicolumn{5}{|c|}{ Metadatos (DCMI) } \\
\hline \multicolumn{5}{|c|}{ Contenido } \\
\hline $\begin{array}{c}\text { ISO } \\
\text { 15836:2009; } \\
\text { ANSI/NISO } \\
\text { Z39.85-2012 }\end{array}$ & 1.22 & $\begin{array}{l}\text { Título. } \\
\text { Etiqueta: DC.Title o equivalente. }\end{array}$ & $\square$ & $\square$ \\
\hline Idem. & 1.23 & $\begin{array}{l}\text { Claves. } \\
\text { Etiqueta: DC.Keywords o } \\
\text { equivalente. }\end{array}$ & $\square$ & $\square$ \\
\hline Idem. & 1.24 & $\begin{array}{l}\text { Descripción. } \\
\text { Etiqueta: DC.Description o } \\
\text { equivalente. }\end{array}$ & $\square$ & $\square$ \\
\hline Idem. & 1.25 & $\begin{array}{l}\text { Lengua. } \\
\text { Etiqueta: DC.Language o } \\
\text { equivalente. }\end{array}$ & $\square$ & $\square$ \\
\hline \multicolumn{5}{|c|}{ Propiedad intelectual } \\
\hline Idem. & 1.26 & $\begin{array}{l}\text { Creador o Autor. } \\
\text { Etiqueta: DC.Creator o equivalente. }\end{array}$ & $\square$ & $\square$ \\
\hline \multicolumn{5}{|c|}{ Instanciación } \\
\hline Idem. & 1.27 & $\begin{array}{l}\text { Identificador del Recurso. } \\
\text { Etiqueta: DC.Identifier o equivalente. }\end{array}$ & $\square$ & $\square$ \\
\hline \multicolumn{5}{|c|}{ Otros Metadatos } \\
\hline Idem. & 1.28 & Etiqueta: DC.Publisher, DC.Type, ... & $\square \quad \square \quad \square$ & $\square$ \\
\hline \multicolumn{5}{|c|}{ Subtotal puntuación Metadatos (DCMI): } \\
\hline \multicolumn{5}{|c|}{ Buscador } \\
\hline--- & 1.29 & Los buscadores encuentran fácilmente & $\square$ & $\square$ \\
\hline --- & 1.30 & $\begin{array}{l}\text { Al usar los términos de búsqueda } \\
\text { usuales e intuitivos relacionados con } \\
\text { la página se obtiene una buena } \\
\text { posición en el buscador. }\end{array}$ & $\square$ & $\square$ \\
\hline
\end{tabular}




\begin{tabular}{|c|c|c|c|}
\hline--- & 1.31 & $\begin{array}{l}\text { Ausencia de obstáculos para los bots } \\
\text { (Tablas, Frames, Flash, } \\
\text { JavaScript...). }\end{array}$ & $\square \quad \square \quad \square \quad \square$ \\
\hline $\begin{array}{l}\text { W3C: } \\
\text { XHTML- } \\
\text { Validator }\end{array}$ & 1.32 & $\begin{array}{l}\text { Test W3C, uso de código estándar } \\
\text { XHTML. }\end{array}$ & $\square \quad \square \quad \square \quad \square$ \\
\hline $\begin{array}{l}\text { W3C: CSS-3 } \\
\text { Validator }\end{array}$ & 1.33 & $\begin{array}{l}\text { Test W3C, uso de código estándar } \\
\text { CSS-3. }\end{array}$ & $\square \quad \square \quad \square \quad \square$ \\
\hline \multicolumn{4}{|c|}{ Subtotal puntuación Buscador: } \\
\hline \multicolumn{4}{|c|}{ Metaetiqueta "Robots" } \\
\hline--- & 1.34 & $\begin{array}{l}<\text { META name="ROBOTS" } \\
\text { content="NOINDEX,NOFOLLOW"> } \\
\text { No deja ni indexar ni seguir los } \\
\text { enlaces. (A) } \\
<\text { META name="ROBOTS" } \\
\text { content="NOINDEX"> } \\
\text { No deja indexar pero sí seguir los } \\
\text { enlaces. (B) } \\
<\text { META name="ROBOTS" } \\
\text { content="NOFOLLOW"> } \\
\text { Deja indexar pero no seguir los } \\
\text { enlaces. (C) } \\
<\text { META name="ROBOTS" } \\
\text { content="INDEX,FOLLOW"> } \\
\text { Deja indexar y seguir los enlaces. (D) }\end{array}$ & $\square \quad \square \quad \square \quad \square$ \\
\hline \multicolumn{4}{|c|}{ Subtotal puntuación Metaetiqueta “ROBOTS”: } \\
\hline \multicolumn{4}{|c|}{ Total puntuación variable dimensional VISIBILIDAD: } \\
\hline
\end{tabular}

Después de la aplicación de la herramienta de medición a las sedes web de los COAATIEs de Andalucía, obtuvimos una serie de resultados que presentamos a continuación agrupados por parámetros. (Gráfico 1)

- Posicionamiento web. En cuanto al posicionamiento sólo las plataformas web de los Colegios de Granada y Sevilla superan la media establecida, obteniendo 14,3 y 10,64 puntos respectivamente de los 21 posibles.

Todos los dominios de las webs son correctos aunque hemos penalizado aquellos que contienen caracteres especiales ya que son más difíciles de recordar, como es el caso de Almería (coaat-al.es) y Sevilla (coaat-se.es), o no figura la provincia en ellas, ya que entendemos que es un dato representativo de los Colegios, como es el caso de Málaga (coaat.es).

Cabe indicar que tan solo el Colegio de Córdoba utiliza keywords y que a 
excepción de las plataformas web de Jaén y Sevilla todas las demás contienen información textual que hace referencia directa a la temática principal en más de un $50 \%$ de contenido.

Otro dato a destacar es que en las plataformas web de los Colegios de Almería y Granada no aparecen ni logo ni el nombre completo de la institución. También que llama la atención que en ninguna de las plataformas web aparecen los iconos de validación de los estándares $\mathrm{W} 3 \mathrm{C}$, un aspecto que otorga valor añadido a los sitios web.

Todos los Colegios coinciden en el PageRank de Google, tienen una puntuación de 5 , valor considerado superior a la media.

Las estimaciones de tráfico para la web de todos los Colegios, atendiendo al Ranking Global Alexa son muy bajas, no estando además ninguno de ellos en el directorio DMOZ.

En cuanto a las redes sociales, todos los Colegios utilizan alguna de las más habituales, principalmente Facebook y Twitter pero sólo el Colegio de Granada utiliza metadatos sociales para facilitar su presencia en esas redes.

- Metadatos. Las plataformas web de los Colegios de Almería, Huelva, Jaén y Málaga no utilizan ningún tipo de metadatos, cuatro Colegios utilizan la metaetiqueta Descripcion, 3 la metaetiqueta Creator y uno Keywords, Title y Language. La metaetiqueta Identifier no es utilizada por ninguno de ellos y sólo Córdoba y Granada utilizan algún otro tipo de metaetiqueta.

- Buscador. En este apartado obtenemos los mejores resultados de los COAATIEs ya que a excepción de la plataforma del Colegio de Cádiz, el resto supera la media.

Utilizando como ecuaciones de búsqueda: "aparejadores" OR "arquitectos técnicos" OR "ingenieros de edificación" OR "colegios aparejadores" AND "provincia", encontramos que todos los Colegios aparecen en los primeros lugares de posicionamiento de los buscadores.

Al pasar los test de cumplimiento del lenguaje XHTML se producen bastantes errores de validación en el código fuente en la mitad de los Colegios (Cádiz, Córdoba, Granada y Málaga). Cabe señalar que a la plataforma del Colegio de Jaén no se le pudo pasar el test de XHTML (indicador 1.32) con ninguno de los tres navegadores que se utilizaron en este trabajo, por lo que esta casilla aparece en blanco, considerando esta circunstancia como negativa.

En cuanto al test de estilos CSS solamente Sevilla y Cádiz no llegarían a la media.

- Metaetiqueta Robots. Si tenemos en cuenta, como ya hemos mencionado anteriormente, que las metaetiquetas facilitan a los motores de búsqueda información sobre sus sitios y que estas en concreto son las que controlan el comportamiento del rastreo y la indexación, llama la atención que sólo el Colegio de Córdoba la utiliza en su plataforma. 
Gráfico 1. Testeo COAATIEs Andalucía: valoración de la visibilidad por parámetros

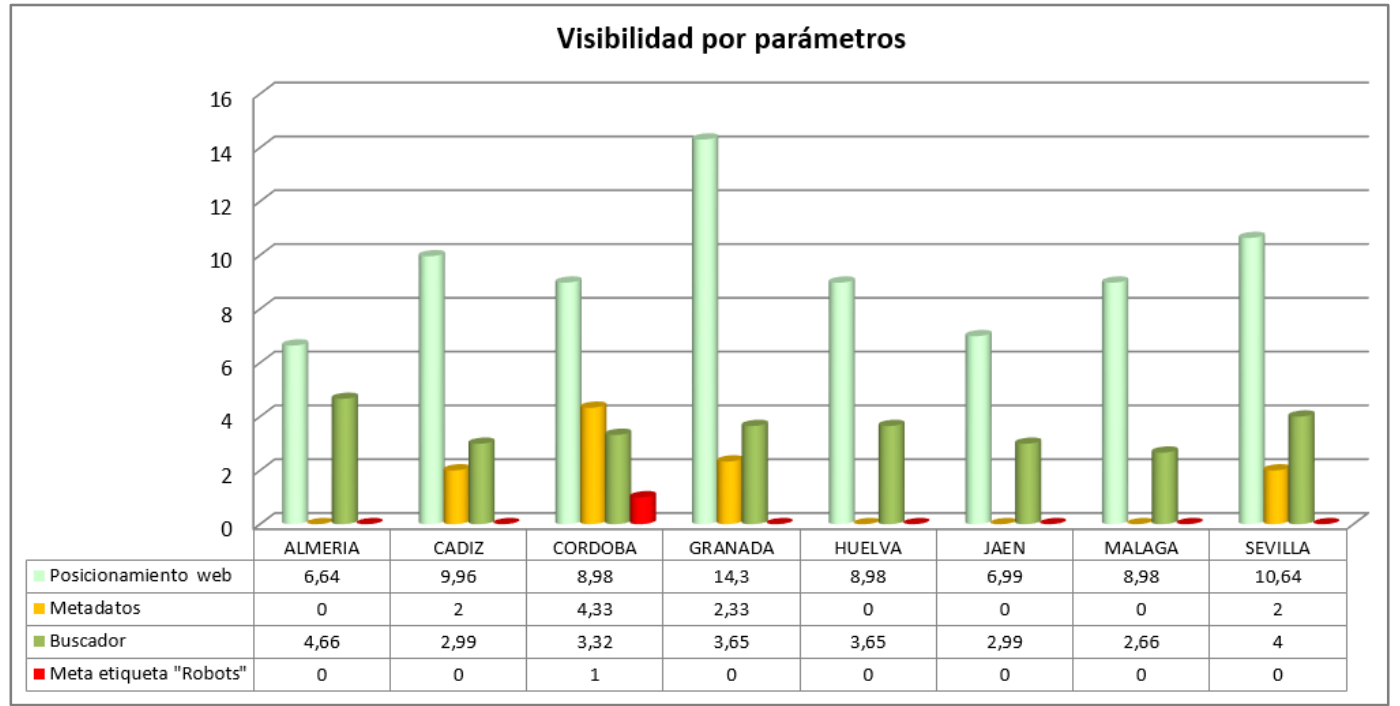

En cuanto al resultado final después de testar las plataformas web de los ocho COAATIEs de Andalucía, podemos indicar que tan sólo el Colegio de Granada $(20,28$ puntos $)$ y el de Córdoba (17,63 puntos) superarían la media posible (17 puntos, sobre un total de 34), quedándose el de Sevilla a 0,36 puntos de conseguirlo. Son, por tanto, las plataformas web de estos tres Colegios los que obtendrían una mayor visibilidad. (Gráfico2)

Gráfico 2. Testeo COAATIEs Andalucía: valoración de la visibilidad por Colegios

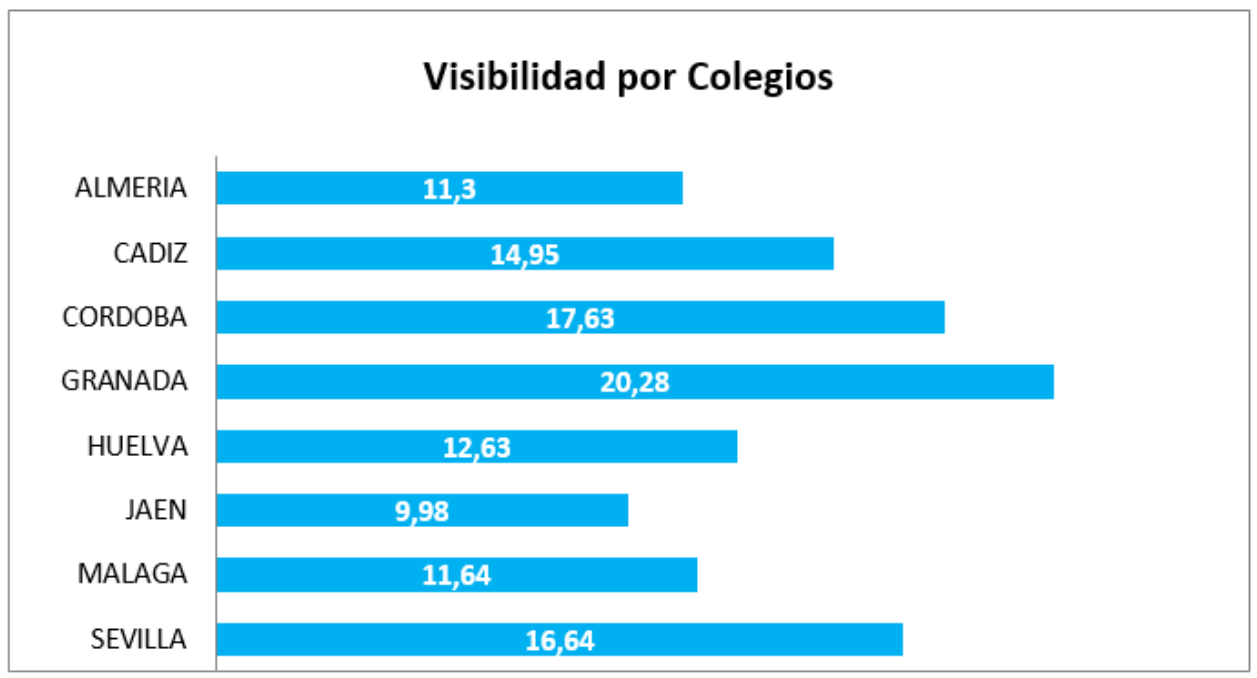


Tabla 2. Resumen de resultados: visibilidad COAATIEs de Andalucía

\begin{tabular}{|c|c|c|c|c|c|c|c|c|}
\hline \multirow[b]{2}{*}{ Parámetros / Indicadores } & \multicolumn{8}{|c|}{ COAATIE'S de Andalucía } \\
\hline & 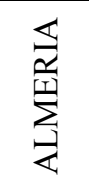 & 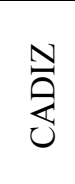 & 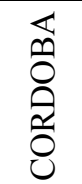 & 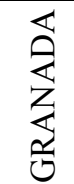 & 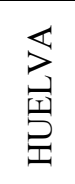 & 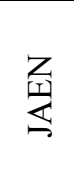 & 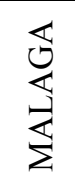 & 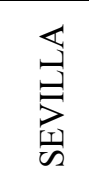 \\
\hline Posicionamiento web & 6,64 & 9,96 & $\mathbf{8 , 9 8}$ & 14,3 & $\mathbf{8 , 9 8}$ & 6,99 & $\mathbf{8 , 9 8}$ & 10,64 \\
\hline 1.01 URL pág. principal & 0,66 & 1 & 1 & 1 & 1 & 1 & 0,33 & 0,66 \\
\hline 1.02 URL pág. secundarias & 1 & 0,66 & 0 & 1 & 1 & 1 & 0 & 0 \\
\hline 1.03 Keywords y densidad & 0 & 0 & 1 & 0 & 0 & 0 & 0 & 0 \\
\hline 1.04 Cadenas keywords & 0 & 0 & 0 & 0 & 0 & 0 & 0 & 0 \\
\hline 1.05 Transparencia & 1 & 1 & 1 & 1 & 1 & 0 & 1 & 0 \\
\hline 1.06 Logo y nombre & 0 & 1 & 1 & 0 & 1 & 1 & 1 & 1 \\
\hline 1.07 Enlaces a otras págs. relac. & 1 & 1 & 1 & 1 & 1 & 1 & 1 & 1 \\
\hline 1.08 Popularidad & 0 & 0 & 0 & 0,66 & 0 & 0 & 1 & 1 \\
\hline 1.09 Rediccionamiento correcto & 0 & 0 & 0 & 1 & 0 & 0 & 0 & 1 \\
\hline 1.10 Actualiz. contenido & 1 & 1 & 1 & 1 & 1 & 1 & 1 & 1 \\
\hline 1.11 Estructuración pág. & 0 & 1 & 1 & 1 & 1 & 1 & 0 & 1 \\
\hline 1.12 Mapa web & 0 & 0 & 0 & 1 & 0 & 0 & 0 & 0 \\
\hline 1.13 Iconos $\mathrm{W} 3 \mathrm{C}$ & 0 & 0 & 0 & 0 & 0 & 0 & 0 & 0 \\
\hline 1.14 Texto alt. imágenes & 0 & 0,33 & 0,33 & 0,66 & 0 & 0 & 0,33 & 0 \\
\hline 1.15 Page Rank & 0,66 & 0,66 & 0,66 & 0,66 & 0,66 & 0,66 & 0,66 & 0,66 \\
\hline 1.16 Factor impacto web FIW & 0,33 & 0,33 & 0,33 & 1 & 0,33 & 0 & 1 & 0,66 \\
\hline 1.17 Estim. tráfico según Alexa & 0,66 & 0,66 & 0,33 & 0,66 & 0 & 0 & 1 & 1 \\
\hline 1.18 Alta en directorio DMOZ & 0 & 0 & 0 & 0 & 0 & 0 & 0 & 0 \\
\hline 1.19 Redes sociales & 0,33 & 0,66 & 0,33 & 1 & 0,33 & 0,33 & 0,33 & 1 \\
\hline 1.20 Metadatos sociales & 0 & 0 & 0 & 1 & 0 & 0 & 0 & 0 \\
\hline 1.21 Optimización móviles & 0 & 0,66 & 0 & 0,66 & 0,66 & 0 & 0,33 & 0,66 \\
\hline Metadatos & $\mathbf{0}$ & 2 & 4,33 & 2,33 & $\mathbf{0}$ & $\mathbf{0}$ & $\mathbf{0}$ & 2 \\
\hline 1.22 Etiqueta Title & 0 & 0 & 0 & 1 & 0 & 0 & 0 & 0 \\
\hline 1.23 Etiqueta Subject & 0 & 0 & 1 & 0 & 0 & 0 & 0 & 0 \\
\hline 1.24 Etiqueta Description & 0 & 1 & 1 & 1 & 0 & 0 & 0 & 1 \\
\hline 1.25 Etiqueta Language & 0 & 0 & 1 & 0 & 0 & 0 & 0 & 0 \\
\hline 1.26 Etiqueta Creator & 0 & 1 & 1 & 0 & 0 & 0 & 0 & 1 \\
\hline 1.27 Etiqueta Identifier & 0 & 0 & 0 & 0 & 0 & 0 & 0 & 0 \\
\hline 1.28 Otros Metadatos & 0 & 0 & 0,33 & 0,33 & 0 & 0 & 0 & 0 \\
\hline Buscador & 4,66 & 2,99 & 3,32 & 3,65 & 3,65 & 2,99 & 2,66 & 4 \\
\hline 1.29 Buscador encuentra. & 1 & 1 & 1 & 1 & 1 & 1 & 1 & 1 \\
\hline 1.30 Posición buscador & 1 & 1 & 1 & 1 & 1 & 1 & 1 & 1 \\
\hline 1.31 Ausencia obstáculos & 1 & 0,33 & 0,66 & 0,66 & 0,33 & 0,33 & 0 & 1 \\
\hline 1.32 Test XHTML & 0,66 & 0,33 & 0 & 0,33 & 0,66 & - & 0 & 1 \\
\hline 1.33 Test CSS-3 & 1 & 0,33 & 0,66 & 0,66 & 0,66 & 0,66 & 0,66 & 0 \\
\hline
\end{tabular}




\begin{tabular}{|r|c|c|c|c|c|c|c|c|}
\hline Metaetiqueta Robots & $\mathbf{0}$ & $\mathbf{0}$ & $\mathbf{1}$ & $\mathbf{0}$ & $\mathbf{0}$ & $\mathbf{0}$ & $\mathbf{0}$ & $\mathbf{0}$ \\
\hline 1.34 Meta name Robots & 0 & 0 & 1 & 0 & 0 & 0 & 0 & 0 \\
\hline TOTALES & $\mathbf{1 1 , 3 0}$ & $\mathbf{1 4 , 9 5}$ & $\mathbf{1 7 , 6 3}$ & $\mathbf{2 0 , 2 8}$ & $\mathbf{1 2 , 6 3}$ & $\mathbf{9 , 9 8}$ & $\mathbf{1 1 , 6 4}$ & $\mathbf{1 6 , 6 4}$ \\
\hline
\end{tabular}

\section{CONCLUSIONES Y RECOMENDACIONES}

La principal conclusión que extraemos de este trabajo es que los COAATIEs de Andalucía son conscientes de la importancia que tiene la utilización de las nuevas tecnologías de Información y Comunicación y han hecho un esfuerzo por adaptarse a las nuevas necesidades tecnológicas dentro de su sector. En mayor o menor medida, todos ellos cumplen con muchos de los indicadores propuestos en la herramienta de medición creada para valorar la visibilidad aunque, en función de los resultados obtenidos, hay unos cuantos aspectos que deben mejorar para incrementar su visibilidad.

El posicionamiento web de las páginas es mejorable porque, aunque existen elementos positivos como la transparencia, el logo, los enlaces exteriores y la estructuración, existen otros aspectos importantes que no se han tenido muy en cuenta: mapa web, keywords, iconos de accesibilidad o texto alternativo en imágenes.

La mayoría de los Colegios no utiliza metadatos, a pesar de ser un elemento sustancial de la metainformación que permite incluir datos relevantes sobre los sitios web.

Los Colegios están presentes en las redes sociales generando así un canal de comunicación con los colegiados y obteniendo a su vez una retroalimentación positiva.

En cuanto a las recomendaciones pensamos que los Colegios deberían mejorar sus sitios web, sobre todo en lo que se refiere a aspectos técnicos y estructurales.

En primer lugar sería conveniente elegir un directorio de posicionamiento ya que aumenta la presencia del sitio web en los motores de búsqueda. Por ejemplo, una búsqueda por palabras clave en Google conducirá más fácilmente hacia la página web si está indexada en algún directorio. Además el enlace directo proporcionado por ese directorio será interpretado como un enlace cualitativo, lo que permitirá mejorar el posicionamiento del propio sitio web.

Se debe evitar la utilización de frames, JavaScript y navegación flash para facilitar el crawling, es decir, el procedimiento utilizado para indexar las páginas de una web siguiendo sus enlaces.

También se debería tener en cuenta un diseño web adaptable a cualquier tipo de dispositivo, ya que esto facilita la visibilidad de cualquier sitio web. Además Google lo tiene en cuenta en sus resultados de búsqueda de las páginas en su versión para dispositivos móviles. 
En esta misma línea de recomendaciones, los COAATIEs deberían concienciarse de la importancia de la evaluación de la calidad de sus sitios web así como de la información que contienen.

Por último pensamos que este trabajo de investigación puede ser útil para los COAATIEs de Andalucía, ya que el uso de las herramientas propuestas en este estudio les permitirá detectar las debilidades y fortalezas de sus portales web respecto a los estándares de las nuevas tecnologías, y en su caso, proceder a su corrección y adaptación paulatina. También servirá para comparar la situación de sus sitios web con respecto al resto de Colegios, tanto en el contenido como en la gestión de la información, con el fin de incrementar la competitividad profesional y el desarrollo y crecimiento de estas corporaciones.

\section{REFERENCIAS BIBLIOGRÁFICAS}

ALMIND, Tomas C. y INGWERSEN, Peter (1997). "Informetric analyses on the world wide web: methodological approaches to "webometrics'". Journal of Documentation, $\mathrm{n}^{\mathrm{o}}$ 4, vol. 53, pp. 404-426. DOI 10.1108/EUM0000000007205. ANGELOZZI, Silvina Marcela y MARTÍN, Sandra Gisela (2011). "Análisis y comparación de metadatos para la descripción de recursos electrónicos en línea". En: III Encuentro Internacional de Catalogadores. Biblioteca Nacional Argentina. Disponible en: <http://eprints.rclis.org/15906/>. [Consulta:30/04/2015].

AYUSO GARCÍA, M ${ }^{\mathrm{a}}$ Dolores y MARTÍNEZ NAVARRO, Victoria (2005). "Protocolo de evaluación de fuentes y recursos informativos en la sociedad del conocimiento: propuestas, enfoques y tendencias". Revista General de Información y Documentación, $\mathrm{n}^{\circ} 1$, vol. 15, pp. 21 - 53. Disponible en: $<$ http://revistas.ucm.es/index.php/RGID/article/view/RGID0505120021A>. [Consulta:20/02/2015].

AYUSO GARCÍA, Ma Dolores y MARTÍNEZ NAVARRO, Victoria (2006). "Evaluación de calidad de fuentes y recursos digitales: guía de buenas prácticas". Anales de documentación, n ${ }^{\circ}$ 9, pp. 17-42. Disponible en: $<$ http://revistas.um.es/index.php/analesdoc/article/view/1841>.

BADRE, Albert N. (2002). Shaping Web Usability: Interaction Design in Context. Reading, MASS: Addison-Wesley Professional [Pearson Education].

BAEZA YATES, Ricardo y RIVERA LOAIZA, Cuauhtémoc (2002). "Ubicuidad y Usabilidad en la Web". Disponible en: $<$ http://users.dcc.uchile.cl/ rbaeza/inf/usabilidad.html $>$. [Consulta:30/04/2015].

BAKER, Loren "Social Media Optimization: 13 Rules of SMO - Search Engine Journal". Disponible en: <http://www.searchenginejournal.com/social-mediaoptimization-13-rules-of-smo/3734/>. [Consulta:19/03/2015]. 
BHARGAVA, Rohit "5 Rules of Social Media Optimization (SMO) | Influential Marketing Blog". Disponible en: $<$ http://www.rohitbhargava.com/2006/08/5_rules_of_soci.html $>$. [Consulta:19/03/2015].

BOUTET, Charles-Victor y QUONIAM, Luc (2012). "Towards Active Seo (Search Engine Optimization) 2.0". Journal of Information Systems and Technology Management, $\mathrm{n}^{\mathrm{o}}$ 3, vol. 9, pp. 443-458. DOI 10.4301/S1807$17752012000300001 . \quad$ Disponible en: $<$ http://www.jistem.fea.usp.br/index.php/jistem/article/view/2124>.

[Consulta:15/04/2015].

BRINK, Tom; GERGLE, Darren y WOOD, Scott D. (2002). Designing web sites that work: Usability for the web. Morgan Kaufmann.

CALDERÓN REHECHO, Andoni (2005). "La evaluación de páginas web". Disponible en: $<$ http://observatorio.cnice.mec.es/modules.php?op=modload\&name=News\&fil $\mathrm{e}=$ article\&sid $=334>$. [Consulta:12/03/2015].

CASTILLO BLANCO, Lourdes; MARTÍNEZ DE PABLO, M.J. y SERVER, Gloria (1999). "Evaluación de la información contenida en seis sedes web de las Escuelas Universitarias y Facultades de Biblioteconomía y Documentación Españolas". Revista española de Documentación Científica, n 3, vol. 22, pp. 325-332. DOI 10.3989/redc.1999.v22.i3.340.

CHANDLER, Kreta y HYATT, Karen (2002). Customer-centered Design: A New Approach to Web Usability. UperSaddle River, NJ: Prentice Hall Professional.

CLAUSON, James (1999). Quality management resources on the internet. Rockville, MD: Goverment Institutes.

CODINA, Lluís (2004). "Posicionamiento web: conceptos y ciclo de vida". Hiipertext.net. Disponible en: $<$ http://eprints.rclis.org/9008/1/Posicionamiento_Web_Conceptos_y_Ciclo_de_ Vida.pdf $>$. [Consulta:1/04/2015].

CODINA, Lluís y MARCOS, Mari-Carmen (2005). "Posicionamiento web: conceptos y herramientas". El Profesional de la Información, $\mathrm{n}^{\circ}$ 2, vol. 14, pp. 84-99. DOI 10.3145/epi.2005.mar.01.

COOKE, Alison (2001). A guide to finding quality information on the Internet: selection and evaluation strategies. 2a ed. London: Library Association Publishing.

CORDÓN GARCÍA, José Antonio et al. (2012). Las nuevas fuentes de información: información y búsqueda documental en el contexto de la web 2.0. 2a ed. Madrid: Pirámide

DE-JUANAS, Angel et al. (2012). "Construcción de un instrumento de verificación de la calidad de portales y redes de investigación de carácter científico en Internet". Revista española de Documentación Científica, $\mathrm{n}^{\circ} 4$, vol. 35, pp. 555-572. DOI 10.3989/redc.2012.4.900. Disponible en: 
$<$ http://redc.revistas.csic.es/index.php/redc/article/view/763>. [Consulta:20/04/2015].

DUSTIN, Elfriede; RASCA, Jeff y MCDIARMID, Douglas (2002). Quality web systems: performance, security, ans usability. Boston: Addison Wesley.

FUENTES MARTÍNEZ, Maria Angélica (2005). "Metadata at the library of the National Congress of Chile: a multidisciplinary experience". En: I International Conference on Dublin Core and Metadata Applicatons. Madrid: Universidad Carlos III, pp. 163-165.

GONZALO PENELA, Carlos (2004). "La selección de palabras clave para el posicionamiento en buscadores". hipertext.net, $\mathrm{n}^{\mathrm{o}} 2$. Disponible en: $<$ http://www.upf.edu/hipertextnet/numero-2/palabras_clave.html $>$. [Consulta:1/05/2015].

GRAHAM, Ian (2002). A pattern Language for Web usability: How to design great websites using software patterns as a guide. Pearson Professional Education.

GRÁVALOS MACHO, David (2013). "La calidad de una página web como herramienta de comunicación". Estudios sobre el mensaje periodístico, $\mathrm{n}^{\mathrm{o}} 19$, pp. 253-261. DOI 10.5209/rev_ESMP.2013.v19.42032. Disponible en: $<\mathrm{http}$ ://ialnet.unirioja.es/servlet/articulo?codigo $=4335679 \&$ info $=$ resumen\&idi oma $=$ SPA $>$. [Consulta:1/08/2015].

GOOGLE: el blog para webmasters. Disponible en: <http://googlewebmasteres.blogspot.com.ar/2009/09/google-no-utiliza-las-palabras-claves.html>. [Consulta:1/02/2015].

HOLMES, Merlyn (2002). Web usability and navigation: a beginner's guide. Berkeley, CA, London: Osborne/McGraw-Hill.

INGWERSEN, Peter (1998). "The calculation of web impact factors". Journal of Documentation, $\mathrm{n}^{\mathrm{o}} 2$, vol. 54, pp. 236-243. DOI 10.1108/EUM0000000007167. JIMÉNEZ PIANO, Marina y ORTÍZ-REPISO JIMÉNEZ, Virginia (2007). Evaluación y calidad de sedes web. Gijón: Trea.

JIMÉNEZ, Sandra Dinora Orantes y CASTILLO, Alejandro Botello (2010). "Calidad y disponibilidad en los servicios Web". Revista Digital Universitaria, $\mathrm{n}^{\mathrm{0}} \quad 3$, vol. 11, pp. 1-9. Disponible en: $<$ http://www.revista.unam.mx/vol.11/num3/art28/int28.htm>.

KRUG, Steve (2001). No me hagas pensar: una aproximación a la usabilidad en la web. Madrid [etc.]: Prentice Hall.

LAMARCA LAPUENTE, María Jesús "Hipertexto, el nuevo concepto de documento en la cultura de la imagen". hipertexto.info. Disponible en: $<\mathrm{http}$ ://www.hipertexto.info/documentos/metadatos.htm $>$.

[Consulta:30/04/2015].

LARA NAVARRA, Pablo; FRANCESC, Saigí y JOSEP M., Duart (2010). "Accesibilidad y usabilidad como un instrumento de competitividad y calidad". Disponible

en: 
$<$ http://reposital.cuaed.unam.mx:8080/jspui/handle/123456789/2285>.

[Consulta:19/03/2015].

LAWRENCE, S. y GILES, C.L. (1999). "Accessibility of information on the web". Nature, vol. 400, no 6740, pp. 107-109. DOI 10.1145/333175.333181.

LÓPEZ, Óscar R. González; PALACIOS, Tomás M. Bañegil y MATEOS, María Buenadicha (2013). "El índice cuantitativo de calidad web como instrumento objetivo de medición de la calidad de sitios web corporativos". Investigaciones Europeas de Direccion y Economia de la Empresa, $\mathrm{n}^{\circ}$ 1, vol. 19, pp. 16-30. DOI 10.1016/j.iedee.2012.07.004.

MARCOS, Mari-Carmen et al. (2006). "Evaluación del posicionamiento web en sistemas de información terminológicos online". hipertext.net, $\mathrm{n}^{\mathrm{o}} 4$. Disponible en: $\quad<\mathrm{http}: / / \mathrm{www} . u p f . e d u / h i p e r t e x t n e t /$ numero-4/posicionamiento.html $>$. [Consulta:5/04/2015].

MARTÍNEZ PESTAÑA, María Jesús (2013). "Políticas de información: desarrollo y estrategias de los programas de la UE e impacto en España". Revista General de Información y Documentación, $\mathrm{n}^{\circ}$ 1, vol. 23, pp. 9-25. DOI 10.5209/rev_RGID.2013.v23.n1.41691. Disponible en: $<$ http://revistas.ucm.es/index.php/RGID/article/view/41691>.

[Consulta:15/01/2015].

MARTÍNEZ USERO, José Ángel (2006). "El uso de metadatos para mejorar la interoperabilidad del conocimiento en los servicios de administración electrónica". El Profesional de la Informacion, n 2, vol. 15, pp. 114-126.

MERLO VEGA, José Antonio (2003). "La evaluación de la calidad de la información web: aportaciones teóricas y experiencias prácticas". En: Recursos informativos: creación, Recursos informativos: creación, descripción y evaluación. Mérida: Junta de Extremadura, pp. 101-110.

MONTENEGRO, Lenin; OCHOA, Verónica y MEJÍA, Mauricio Espinoza (2014). "Mejorando la visibilidad de sitios Web usando tecnología semántica". En: TIC.EC - Congreso Ecuatoriano de Tecnologías de la Información y Comunicaciones. Maskana, I+D+Ingeniería, pp. 139-150. Disponible en: $<\mathrm{http}: / /$ dspace.ucuenca.edu.ec/handle/123456789/21397>.

[Consulta:19/02/2015].

MORVILLE, Peter (2004). "Diseño de experiencias del usuario". Disponible en: $<$ http://iainstitute.org/es/translations/000370.html >. [Consulta:19/03/2015].

NIELSEN, Jakob (2000). Usabilidad: Diseño de sitios Web. Madrid: Pearson Educación

NIELSEN, Jakob y TAHIR, Marie (2003). Usabilidad de páginas de inicio: análisis de 50 sitios web. Madrid: Pearson Educación.

ODDEN, Lee "New Rules for Social Media Optimization". Disponible en: $<$ http://www.toprankblog.com/2006/08/new-rules-for-social-mediaoptimization/>. [Consulta:19/03/2015]. 
OLTHIUS, Cameron "Miami SEO Company - Put Your Business on Steroids!". Disponible en: $<$ http://www.pronetadvertising.com/>. [Consulta:19/03/2015].

OWYANG, Jeremiah "Rules of Social Media Optimization | Web Strategy by Jeremiah Owyang | Digital Business". Disponible en: <http://www.webstrategist.com/blog/2006/08/13/rules-of-social-media-optimization/>. [Consulta:19/03/2015].

PEARROW, Mark (2002). The wireless web usability handbook. Hingham, MASS: Charles River.

PINTO MOLINA, María et al. (2004). "Análisis cualitativo de la visibilidad de la investigación de las universidades españolas a través de sus páginas web". Revista Española de Documentación Científica, $\mathrm{n}^{\circ}$ 3, vol. 27, pp. 345-370. DOI 10.3989/redc.2004.v27.i3.157.

Disponible

en: $<$ http://search.proquest.com/docview/57595569?accountid=14542>. [Consulta:20/04/2015].

PINTO MOLINA, María; GARCÍA MARCO, F. Javier y AGUSTÍN LACRUZ, María del Carmen (2002). Indización y resumen de documentos digitales y multimedia: técnicas y procedimientos. Gijón: Trea.

RODRIGUEZ I GAIRÍN, J.M. (1997). "Valoración del impacto de la información en Internet : Altavista, el Citation Index de la red". Revista española de documentación científica, $\mathrm{n}^{\mathrm{o}}$ 2, vol. 20, pp. 175-181. Disponible en: $<$ http://cat.inist.fr/?aModele $=$ afficheN\&cpsidt $=2740561>$.

[Consulta:14/08/2015].

RODRÍGUEZ MARTÍNEZ, Ruth; CODINA, Lluís y PEDRAZA JIMÉNEZ, Rafael (2012). "Indicadores para la evaluación de la calidad en cibermedios: análisis de la interacción y de la adopción de la Web 2.0". Revista española de Documentación Científica, $\mathrm{n}^{\mathrm{o}} 1$, vol. 35, pp. 61-93. DOI 10.3989/redc.2012.1.858.

SANZ CABALLERO, Isabel y FABA PÉREZ, Cristina (2012). "Diseño de un modelo basado en criterios e indicadores de características para la evaluación de los sitios webs de archivos". Revista General de Información y Documentación, vol. 22, pp. 307-331. ISSN 1988-2858. DOI 10.5209/rev_RGID.2012.v22.39660. Disponible
$<$ http://revistas.ucm.es/index.php/RGID/article/view/39660>. [Consulta:26/07/2015].

SANZ CABALLERO, Isabel María y FABA PÉREZ, Cristina (2010). "El factor de impacto Web de los archivos universitarios latinoamericanos: la fiabilidad de los motores de búsqueda para calcularlo". Investigación bibliotecológica, $\mathrm{n}^{\mathrm{o}}$ 50, vol. 24, pp. 157-181. Disponible en: $<$ http://www.scielo.org.mx/scielo.php?script=sci_arttext\&pid=S0187358X2010000100009\&lng=es\&nrm=iso\&tlng $=$ es $>$. [Consulta:14/08/2015].

SENSO, José A. y ROSA PIÑERO, Antonio de la (2003). "El concepto de metadato: algo más que descripción de recursos electrónicos". Ciência da 
Informação, $\quad \mathrm{n}^{\mathrm{o}} \quad 2$, vol. $32, \quad$ pp. $\quad 95-106$. DOI $\quad 10.1590 / \mathrm{S} 0100-$ 19652003000200011.

SMITH, Alastair (1997). "Testing the Surf: Criteria for Evaluating Internet Information Resources". PublicAccess Computer Systems Review, $\mathrm{n}^{\circ}$ 3, vol. 8, pp. 1-14. Disponible en: <http://epress.lib.uh.edu/pr/v8/n3/smit8n3.html>. [Consulta: 10/05/2007].

SMITH, Alastair (2003). "Homepage Usability: 50 Web sites Deconstructed". Online Information Review, $\mathrm{n}^{\circ}$ 4, vol. 27, pp. 293-294. ISSN 1468-4527. DOI $10.1108 / 14684520310489140$.

Disponible en: $<$ http://www.emeraldinsight.com/doi/abs/10.1108/14684520310489140>.

SMITHSON, Steve; DEVECE, Carlos Alberto y LAPIEDRA, Rafael (2010). "Online visibility as a source of competitive advantage for small-and mediumsized tourism accommodation enterprises". The Service Industries Journal, $\mathrm{n}^{\mathrm{o}}$ 10, vol. 31, pp. 1573-1587. DOI 10.1080/02642069.2010.485640. Disponible en:

$<$ http://www.tandfonline.com/doi/full/10.1080/02642069.2010.485640\#previe w>. [Consulta:10/03/2015].

SPOOL, Jared (1999). Web site usability: a designer's guide. San Francisco: Morgan Kaufman Publishers.

VALLE GARCÍA, Diana del (2013). "La Ley 11/2007, de Acceso Electrónico de los Ciudadanos a los Servicios Públicos y el uso del software libre en la Administración Pública". Revista General de Información y Documentación, $\mathrm{n}^{\circ}$ 1, vol. 23, pp. 27-42. DOI 10.5209/rev_RGID.2013.v23.n1.41692. Disponible en: $\quad<$ http://revistas.ucm.es/index.php/RGID/article/view/41692>. [Consulta:26/07/2015].

VANTI, Nadia; COSTA, José Alfredo F. y OLIVEIRA DA SIVA, Ilaydiany Cristina (2013). "Nova fórmula revisada para o cálculo do fator de impacto WEB (FIW)". Liinc em Revista, $\mathrm{n}^{\circ}$ 1, vol. 9, pp. 228-236.

WROBLEWSKI, Luke (2002). Site-Seeing: A Visual Approach To Web Usability. New York, NY: Hungry Minds. 